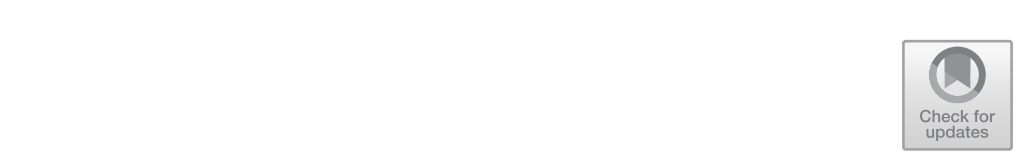

\title{
Erratum to: Media Logic(s) Revisited
}

\author{
Caja Thimm, Mario Anastasiadis \\ and Jessica Einspänner-Pflock
}

\section{Erratum to: \\ C. Thimm et al. (eds.), Media Logic(s) Revisited, Transforming Communications - Studies in Cross-Media Research, https://doi.org/10.1007/978-3-319-65756-1}

The original version of the book was inadvertently published prematurely before incorporating the final corrections due to an error in the production process. The version supplied here has been corrected and approved by the author [authors].

The updated online version of this book can be found at https://doi.org/10.1007/978-3-319-65756-1

(C) The Author(s) 2018

El

C. Thimm et al. (eds.), Media Logic(s) Revisited, Transforming

Communications - Studies in Cross-Media Research, https://doi.org/10.1007/978-3-319-65756-1_14 